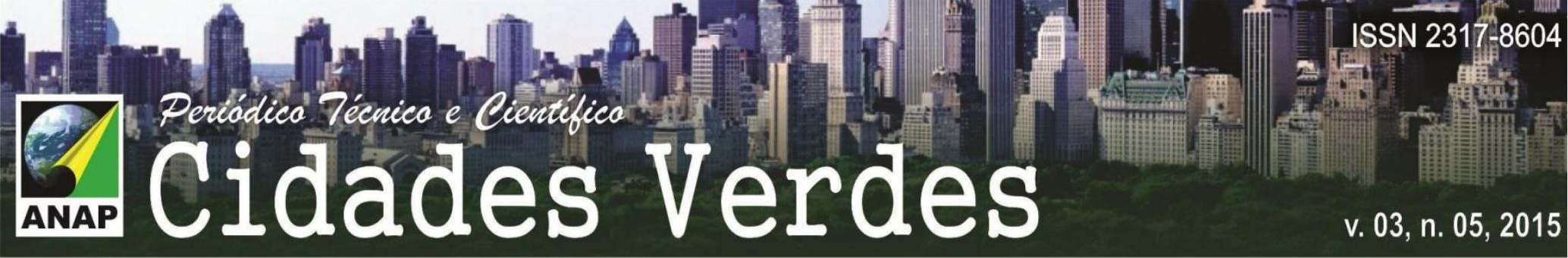

\title{
PARQUES E PROTEÇÃO AMBIENTAL NO VETOR OESTE DA REGIÃO METROPOLITANA DE SÃO PAULO
}

\author{
Leonardo Loyolla Coelho ${ }^{1}$
}

Francine Gramacho Sakata ${ }^{2}$

\section{RESUMO}

No vetor oeste da região metropolitana de São Paulo, dentre suas superfícies protegidas, há parques urbanos e Unidades de Proteção Integral ou Uso Sustentável, que contam com administrações específicas, o que não significa que não existam dificuldades para sua manutenção. Estas áreas representam uma porcentagem pequena do total de zonas de proteção ambiental, protegidas unicamente pela legislação, mas sem delimitação, gestão ou uso. Observou-se que, enquanto parques e unidades de proteção têm maior garantia de sua integridade, as zonas de proteção da legislação estão, na prática, desprotegidas. Para o público, são terras sem nome, de um proprietário oculto, aguardando destinação. O reconhecimento como logradouros para fruição pública junto com a criação de uma estrutura jurídica e de gestão seriam chaves para a proteção de recursos naturais em áreas muito urbanizadas.

PALAVRAS-CHAVE: Superfícies protegidas, Parque Urbano, Paisagismo, Sistemas de Espaços Livres

\section{PARKS AND ENVIRONMENTAL PROTECTION IN THE METROPOLITAN REGION OF WEST VECTOR SAO PAULO}

\footnotetext{
${ }_{1}^{1}$ Arquiteto e Urbanista, Doutor FAU USP. Iloyolla@gmail.com

${ }^{2}$ Arquiteta e Urbanista, Doutoranda FAU USP. francinesakata@gmail.com
} 


\section{ABSTRACT}

In the west sector of São Paulo metropolitan area, among the protected areas, there are urban parks and Integral Protection Units and Sustainable Use. They have specific administration, which does not mean that there are no difficulties for its maintenance. These areas represent a small percentage of total environmental protection zones, guaranteed only by the legislation but without delimitation, management or use. It was observed that, while parks and protection units have greater assurance of their integrity, the legislation protection zones are in practice unprotected. For the public, they are nameless land, with a hidden owner, awaiting any kind of use. The recognition as public parks for public enjoyment along with the creation of a legal framework and management would be keys for the protection of natural resources in very urbanized areas.

KEYWORDS: Protected Areas, Urban Park, Landscape, Space Systems Free

\section{PARQUES Y PROTECCIÓN DEL MEDIO AMBIENTE EN LA REGIÓN METROPOLITANA DE OESTE VECTOR SAO PAULO}

\section{RESUMEN}

En la área occidental de la región metropolitana de São Paulo, entre sus áreas protegidas, hay parques urbanos y Unidades de Protección Integral y Aprovechamiento Sustentable, que tienen administraciones específicas, lo que no significa que no hay dificultades de mantenimiento. Estas áreas representan un pequeño porcentaje de total de zonas de protección del medio ambiente, protegidos por la legislación pero sin delimitación, la gestión o el uso. Se observó que, mientras que los parques y unidades de protección tienen una mayor garantía de su integridad, las zonas de protección de la legislación, en la práctica estan desprotegidas. Para el público, son tierra sin nombre, de un propietario oculto, en espera de destinación. El reconocimiento como parques públicos para el disfrute del público, junto con la creación de un marco jurídico y la gestión, sería clave para la protección de los recursos naturales en zonas muy urbanizadas.

PALABRAS CLAVE: Áreas Protegidas, Parque Urbano, Paisaje, Sistema de Espacios Libres 


\section{Introdução}

Há parques urbanos que são criados em torno da conservação de um bosque remanescente ou uma lagoa. E há áreas de conservação que podem ou não comportar usos de recreação e lazer. Mas, em todos os casos, é a fruição humana que garante atenção e recursos para a proteção de um recurso natural. Quanto mais útil as pessoas percebem um lugar, maior a garantia de manutenção da qualidade de seus atributos ambientais.

No vetor oeste da Região Metropolitana de São Paulo (RMSP) - cujo recorte adotado compreende os municípios de Barueri, Carapicuíba, Cotia, Embu das Artes, Itapevi, Itapecerica da Serra, Jandira, Santana de Parnaíba e Vargem Grande Paulista - dentre as áreas identificadas como 'superfícies protegidas'3, encontram-se os parques urbanos, que podem ser municipais ou estaduais, as reservas e as áreas classificadas de acordo com o Sistema Nacional de Unidades de Conservação como Unidades de Proteção Integral (Reserva Biológica Tamboré) ou Uso Sustentável (Reserva Particular do Patrimônio Natural Sítio Ryan e Voturuna I e II).

Mesmo com as dificuldades de fiscalização e de manutenção, o fato de haver alguma estrutura de administração garante uma efetividade muito maior na proteção dos recursos naturais. Porém, com exceção daquelas que se caracterizam como parques urbanos, não existem, em geral, ações de apropriação efetiva sobre as áreas de conservação e preservação legalmente estabelecidas no vetor.

\section{Objetivos}

Identificar, no vetor oeste da RMSP, os parques e unidades de conservação, verificando acessos, infraestrutura, usos e estado de proteção. Confrontar a

\footnotetext{
${ }^{3}$ Tardin (2008) as define como "as superfícies livres submetidas a uma medida legal de proibição da ocupação urbana" (p.168)
} 
condição dessas áreas com aquelas protegidas unicamente pela legislação ambiental mas sem uso público e sem gestão específica.

\section{Metodologia}

Pesquisa junto a órgãos públicos e leitura da legislação que incide sobre os parques, as unidades de conservação e as zonas protegidas. Observação da realidade "in loco" (por meio de visitas de campo e sobrevoos) e por meios secundários (análise de mapas e fotografias).

\section{Resultados}

\subsection{Caracterização}

Embora existam no vetor mecanismos legais abrangendo aproximadamente a metade da área correspondente à soma dos municípios estudados ${ }^{4}$, os parques e as unidades de proteção correspondem a pequenas porcentagens $\left(135 \mathrm{~km}^{2}\right.$, ou cerca de $\left.31 \%\right)$ desse total de zonas ambientalmente protegidas (figura 1 e tabela 1).

\footnotetext{
${ }^{4}$ A soma das áreas abrangidas, na esfera estadual, pelas Áreas de Proteção Ambiental Itupararanga e Várzea do Tietê e pela Área de Proteção e Recuperação dos Mananciais - Guarapiranga e, na esfera municipal, pelas áreas protegidas definidas pelos planos diretores e leis de uso e ocupação do solo municipais corresponde a $429 \mathrm{~km}^{2}$ ( $45 \%$ do vetor).
} 


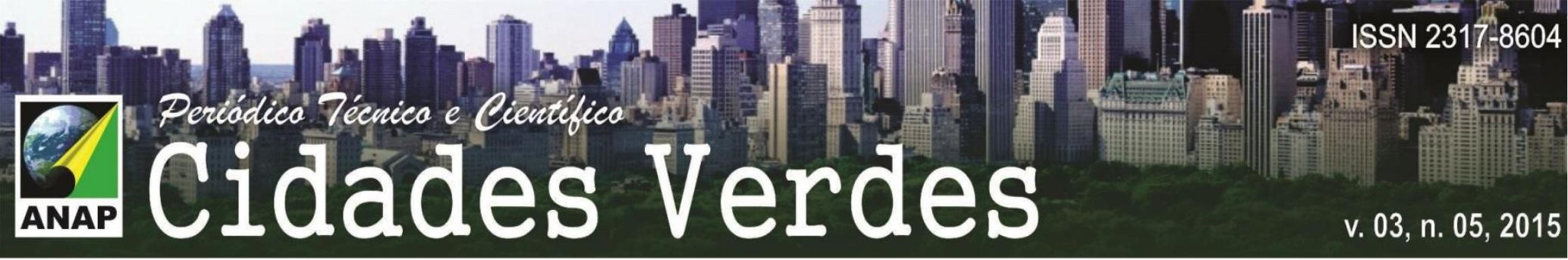

Figura 1: Superfícies protegidas do vetor oeste da RMSP.

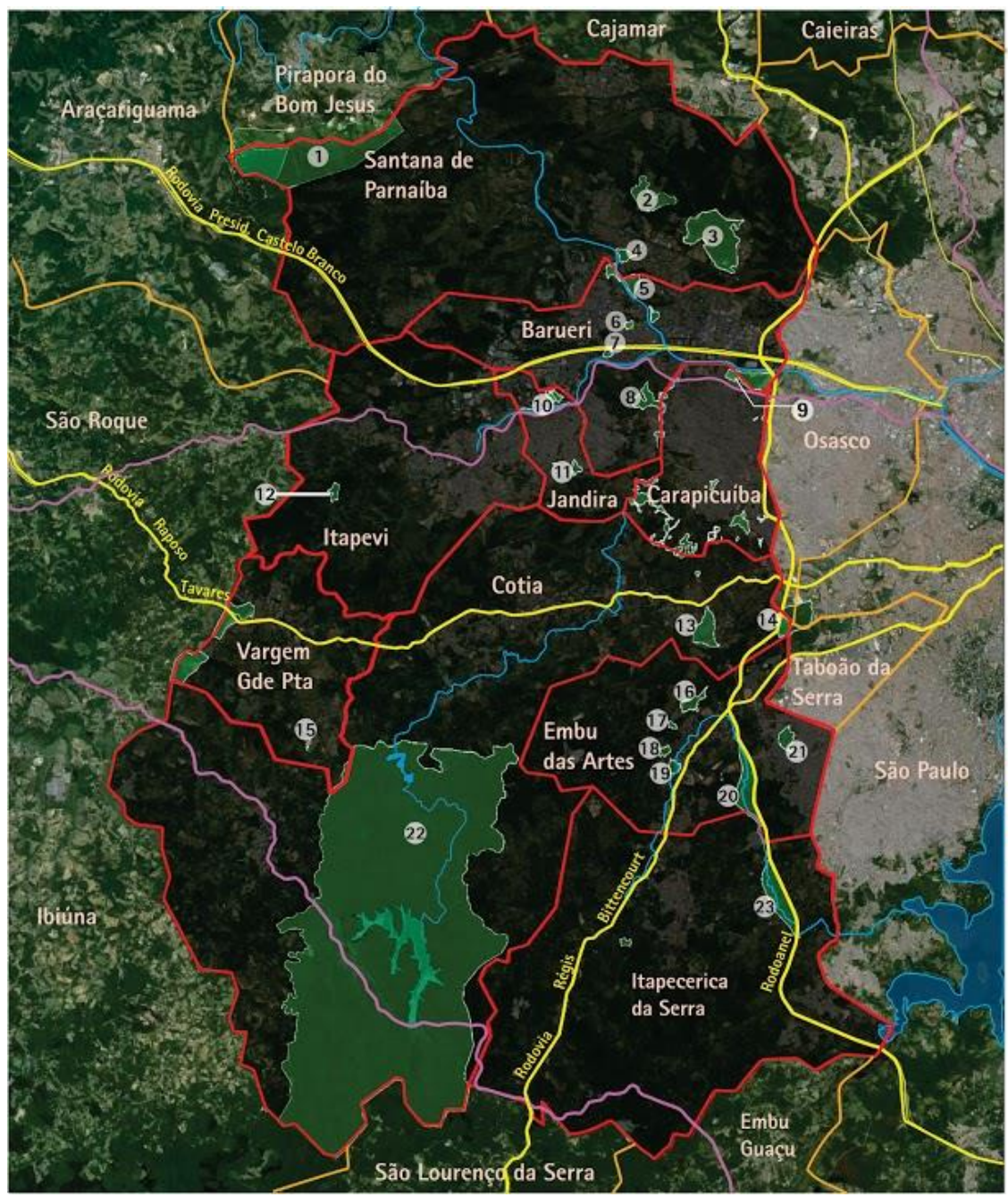

Superficies protegidas

1 Área Natural Tombada do Boturuna

2 Reserva Gênesis

3 Reserva Biológica Tambore

4 Parque Lagoa do Bacuri

5 Parque Ecológico do Tietê Centro

de Lazer llha do Tamboré

6 Parque Municipal Dom José

7 Parque da $3^{\text {a Idade }}$

8 Área do Exército

9 Parque Estadual Gabriel Chucre/

Parque da Lagoa

10 Área de Lazer do Trabalhador

11 Portal Ecológico

12 RPPN Sítio Ryan

13 Parque CEMUCAM

14 Parque Tizo

15 Parque Lagoa do Agreste

16 APA Prado Rangel

17 Fonte dos Jesuitas

18 APA Lagoa dos Principes

19 Parque Francisco Rizzo

20 Parque Rodoanel - Embu da Artes

21 APA Santa Tereza

22 Reserva Morro Grande

23 Parque Compensatório Rodoanel

- Limite municipios Vetor Oeste

- Demais municipios RMSP

- Rodovias

- Principais corpos d'água

- Linha férrea

II Casario

Montagem dos autores e de Viviane Ribeiro Viana. sobre imagem Google Earth, 2014

Tabela 1 - Áreas das superfícies protegidas do vetor oeste em 2014. Elaborado pelos autores e por Viviane Ribeiro Viana com base nos planos diretores e leis de uso e ocupação municipais

\begin{tabular}{|c|c|c|c|}
\hline Município & Nome & Área (ha) & $\begin{array}{c}\text { \% da área } \\
\text { total do } \\
\text { município }\end{array}$ \\
\hline \multirow{7}{*}{ Barueri } & Parque Municipal Dom José & 8,4 & \\
\hline & Parque da $3^{\text {a }}$ Idade & 9,9 & \\
\hline & Área do Exército & 55,6 & \\
\hline & Chácaras Val Paraíso & 17,7 & \\
\hline & $\begin{array}{l}\text { Parque Ecológico do Tietê Centro de Lazer llha } \\
\text { do Tamboré }\end{array}$ & 35 & \\
\hline & Área do Parque Ecológico do Tietê & 12,9 & \\
\hline & TOTAL & 139,54 & 2,2 \\
\hline
\end{tabular}




\begin{tabular}{|c|c|c|c|}
\hline Município & Nome & Área (ha) & $\begin{array}{c}\% \text { da área } \\
\text { total do } \\
\text { município }\end{array}$ \\
\hline \multirow{5}{*}{ Carapicuíba } & Parque da Lagoa de Carapicuíba & 16 & \\
\hline & Parque dos Paturis & 22,44 & \\
\hline & Parque da Aldeia de Carapicuíba & 31 & \\
\hline & $\begin{array}{l}\text { Áreas previstas para implantação de parques } \\
\text { lineares na porção sul do município }\end{array}$ & 58,97 & \\
\hline & TOTAL & 128,41 & 3,7 \\
\hline \multirow{6}{*}{ Cotia } & Reserva Morro Grande & $10.876,50$ & \\
\hline & Parque das Nascentes & 16,9 & \\
\hline & Parque Jequitibá & 43,2 & \\
\hline & Parque Teresa Maia & 2,5 & \\
\hline & Parque CEMUCAM & 96,4 & \\
\hline & TOTAL & $11.035,40$ & 34,1 \\
\hline \multirow{7}{*}{ Embu } & APA Santa Tereza & 42,9 & \\
\hline & Parque Várzea do Embu Mirim (Rodoanel) & 160 & \\
\hline & APA Lagoa dos Príncipes & 15,2 & \\
\hline & APA Prado Rangel & 39,4 & \\
\hline & Parque Francisco Rizzo & 21,7 & \\
\hline & Fonte dos Jesuítas & 6,6 & \\
\hline & TOTAL & 285,77 & 4,1 \\
\hline \multirow{3}{*}{$\begin{array}{l}\text { Itapecerica } \\
\text { da Serra }\end{array}$} & Parque Compensatório Rodoanel & 181 & \\
\hline & Parque Ecológico Represinha & 4,3 & \\
\hline & TOTAL & 185,3 & 1,2 \\
\hline \multirow[t]{2}{*}{ Itapevi } & RPPN Sítio Ryan & 19,47 & \\
\hline & TOTAL & 19,47 & 0,2 \\
\hline \multirow{5}{*}{ Jandira } & Área de Lazer - Cidade da Família & 8,14 & \\
\hline & Várzea Rio São João & 27,44 & \\
\hline & $\begin{array}{l}\text { Sítio Pedra Bonita / Pq Natural Municipal Portal } \\
\text { Ecológico }\end{array}$ & 11,84 & \\
\hline & Pedreira do Mirante & 0,61 & \\
\hline & TOTAL & 48,02 & 2,8 \\
\hline \multirow{8}{*}{$\begin{array}{l}\text { Santana de } \\
\text { Parnaíba }\end{array}$} & Reserva Biológica Tamboré & 367,34 & \\
\hline & Reserva Gênesis & 60 & \\
\hline & Reserva Burle Marx & 130 & \\
\hline & Área Natural Tombada do Boturuna & $1.065,15$ & \\
\hline & Parque Lagoa do Bacuri & 24,33 & \\
\hline & RPPN Voturuna I & 66,55 & \\
\hline & RPPN Voturuna II & 58,45 & \\
\hline & TOTAL & $1.771,82$ & 9,8 \\
\hline \multirow{2}{*}{$\begin{array}{l}\text { Vargem } \\
\text { Grande } \\
\text { Paulista }\end{array}$} & Parque Lagoa do Agreste & 2,91 & \\
\hline & TOTAL & 2,91 & 0,1 \\
\hline
\end{tabular}




\subsection{Reservas}

A maior extensão contínua de superfície protegida no vetor é a Reserva Florestal do Morro Grande, que corresponde a quase $12 \%$ das áreas dos municípios do recorte, cerca de $90 \%$ da área de superfícies protegidas do vetor e a um terço do município de Cotia, no qual está inserida. A reserva foi criada pela Lei Estadual 1.949/1979 com objetivo de preservar a nascente do Rio Cotia e o Reservatório Pedro Beicht e está sob responsabilidade da Companhia de Saneamento Básico do Estado de São Paulo (SABESP). Está inserida na Área de Proteção de Mananciais da Região Metropolitana de São Paulo e é considerada "core" da Reserva da Biosfera do Cinturão Verde da Cidade de São Paulo, coordenada pelo Instituto Florestal da Secretaria do Meio Ambiente do Estado de São Paulo. Corresponde à categoria de proteção máxima em relação às áreas de preservação estaduais.

O município de Santana de Parnaíba também abriga áreas significativas, dentre as quais destacam-se a Área Natural Tombada do Boturuna, Reservas Particulares do Patrimônio Natural (RPPNs) e reservas municipais.

Estas últimas foram estabelecidas por meio de contrapartidas legais resultantes da implantação de loteamentos fechados e condomínios horizontais, dinâmica de urbanização recorrente em diversos municípios do vetor, sobretudo em Barueri, Cotia e Vargem Grande Paulista, além de Santana de Parnaíba. Tal expediente permitiu ampliar a quantidade de áreas ambientalmente protegidas em âmbito municipal por meio do processo de aprovação de loteamentos fechados de médio e alto padrão.

São resultantes desse processo as reservas Burle Marx, Gênesis e Tamboré, cujas gestões foram entregues aos respectivos empreendimentos que as geraram. Embora resultem de obrigações legais, essas áreas são utilizadas pelos empreendedores como elemento agregador de valor para seus empreendimentos, que incluem em suas propagandas a existência de uma bem-vinda proximidade e de relações visuais com essas reservas. 


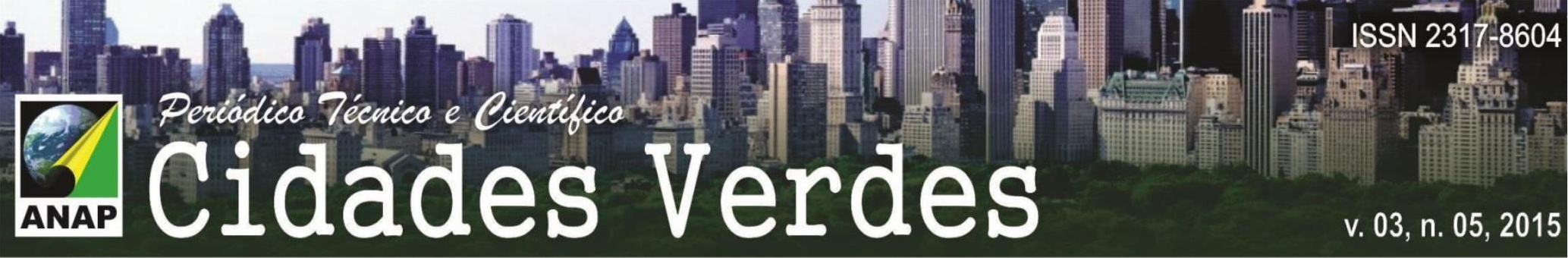

Tais iniciativas são poucas e isoladas em relação ao conjunto do vetor, sendo que a maioria dos demais empreendimentos residenciais para alta e média renda se nivelam pelos parâmetros mínimos da legislação, sem protagonizar inovações.

Mas vale destacar que, mesmo no loteamento Alphaville Burle Marx, a mata é acessível apenas visualmente e isolada fisicamente dos moradores e do entorno por muros e cercas.

Figura 2: Reserva Alphaville Burle Marx.

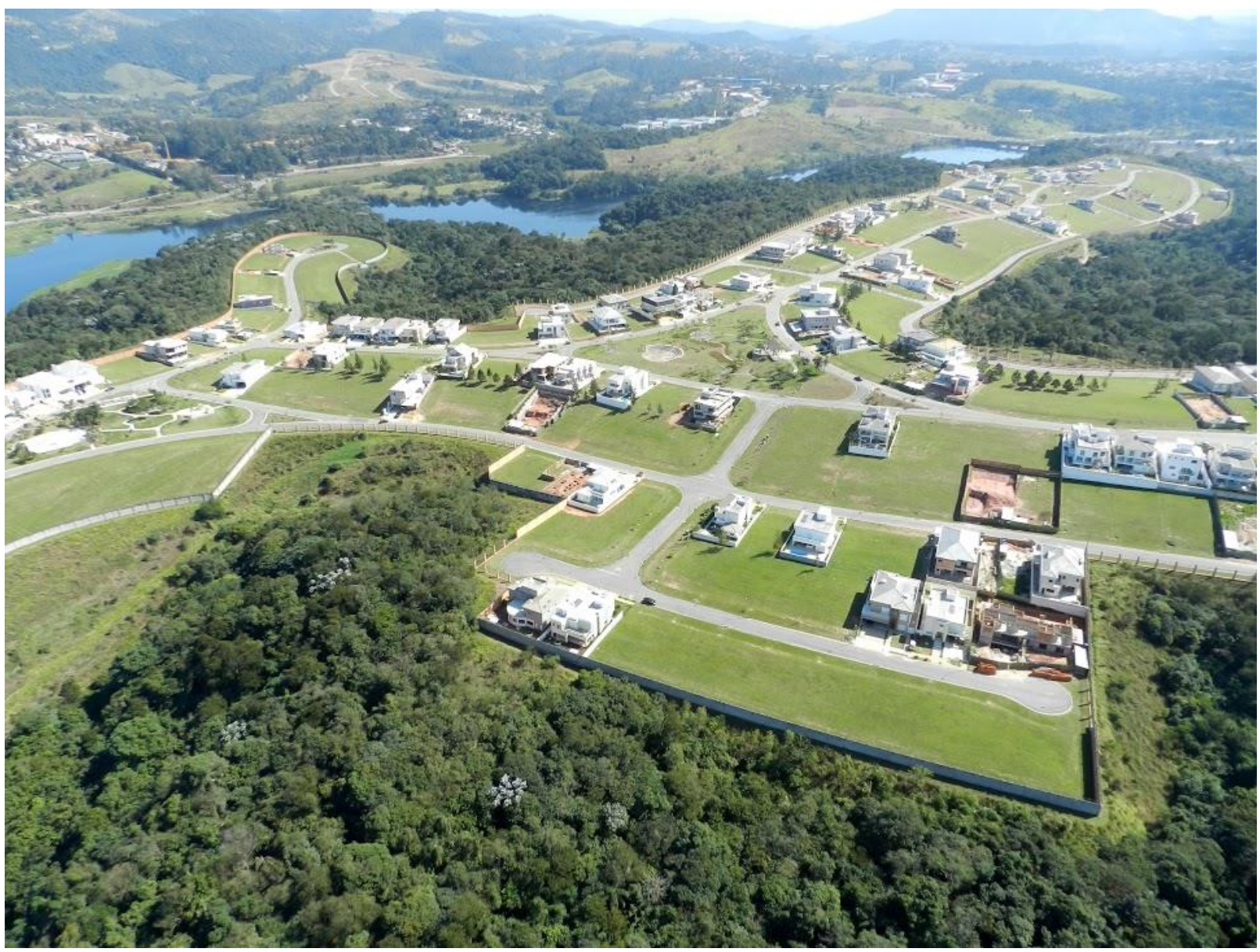

Foto dos autores, 2013

A Área Natural Tombada (ANT) Serra do Boturuna possui tombamento pelo Conselho de Defesa do Patrimônio Histórico, Arqueológico, Artístico e Turístico (CONDEPHAAT) devido ao seu valor paisagístico, ambiental, turístico e histórico. 


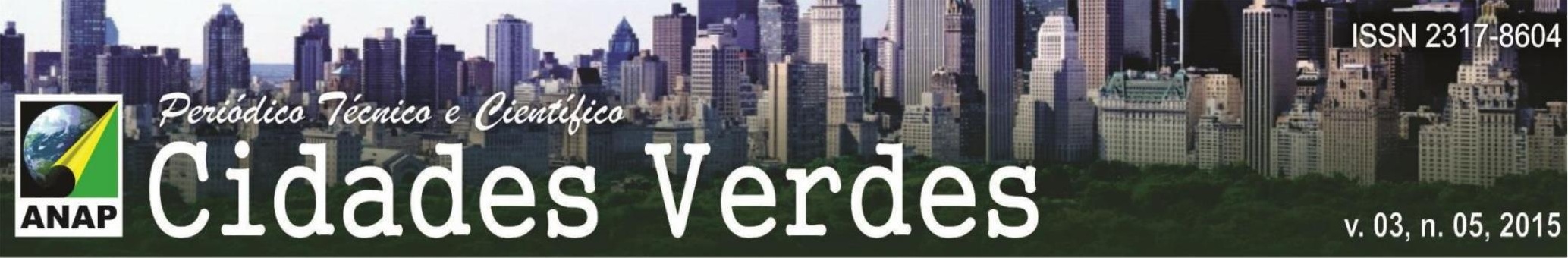

Além de Santana de Parnaíba, abrange também os municípios de Araçariguama e Pirapora de Bom Jesus.

Figura 3: Serra do Boturuna, município de Santana de Parnaíba.

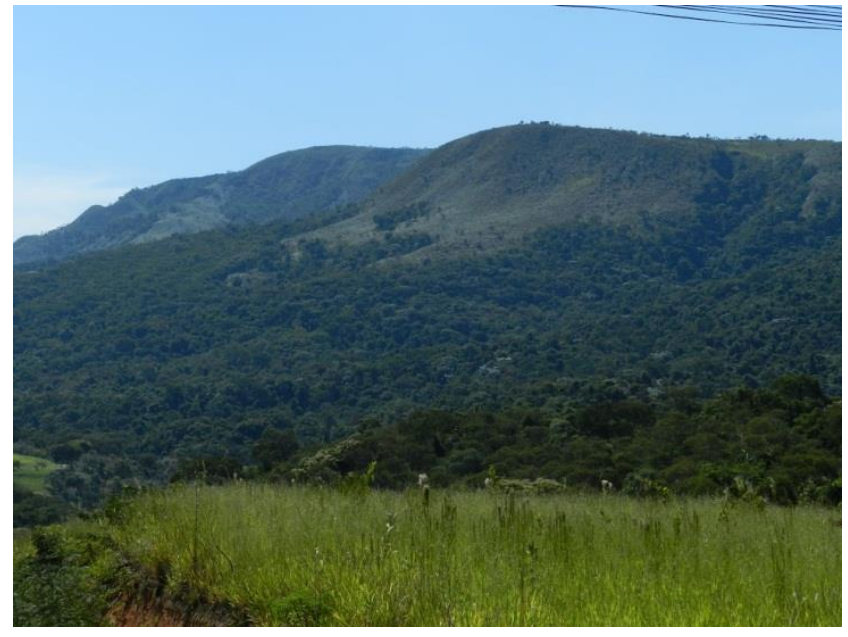

Foto dos autores, 2014

Em 2013 a proteção da área foi reforçada em Santana de Parnaíba por meio da criação do Território de Preservação Ambiental do Voturuna e Manancial do Santo André ${ }^{5}$, pelo qual veda-se a aprovação de quaisquer tipos de edificação em seu perímetro até que seja revisada a Lei de Uso e Ocupação desse município.

\subsection{Parques urbanos}

Em Santana de Parnaíba, o Parque Ecológico do Tietê Centro de Lazer Ilha do Tamboré é uma área na qual incidem simultaneamente mecanismos de restrição à ocupação urbana - zona de proteção ambiental municipal e APA estadual - e a função de superfície protegida, sendo também utilizado para finalidades recreativas. A administração do local é realizada por meio do Departamento de Águas e Energia Elétrica. Seu projeto data de 1979, sendo um trecho de um parque linear que se estenderia até a nascente do Rio Tietê, no município de Salesópolis. Do projeto original foram executadas apenas esta parte e

${ }^{5}$ Lei $3.297 / 2013$ 


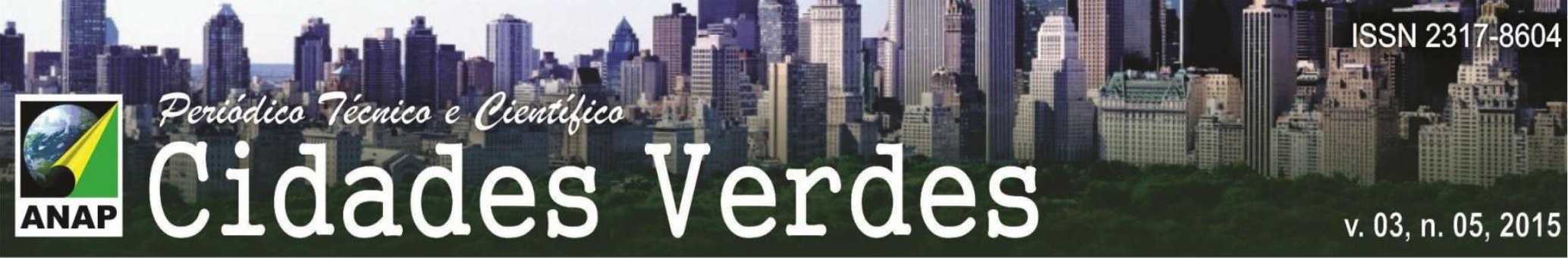

o Núcleo Engenheiro Goulart, na divisa entre os municípios de São Paulo e Guarulhos.

O programa de atividades do parque contempla campos de futebol, áreas para churrasco, brinquedos e um extenso lago. A área possui acessibilidade restrita para pedestres, pois se situa isolada entre o loteamento fechado Tamboré (que dá as costas para o parque) e o Rio Tietê, não contando com passarelas que façam conexão com a margem oposta, na qual se localizam bairros de menor renda, cuja população, a priori, apresenta maiores demandas por espaços recreativos. Ou seja, os usuários precisam de carros para usufruir da área.

Figuras 4 e 5: Parque Ecológico do Tietê Centro de Lazer llha do Tamboré.

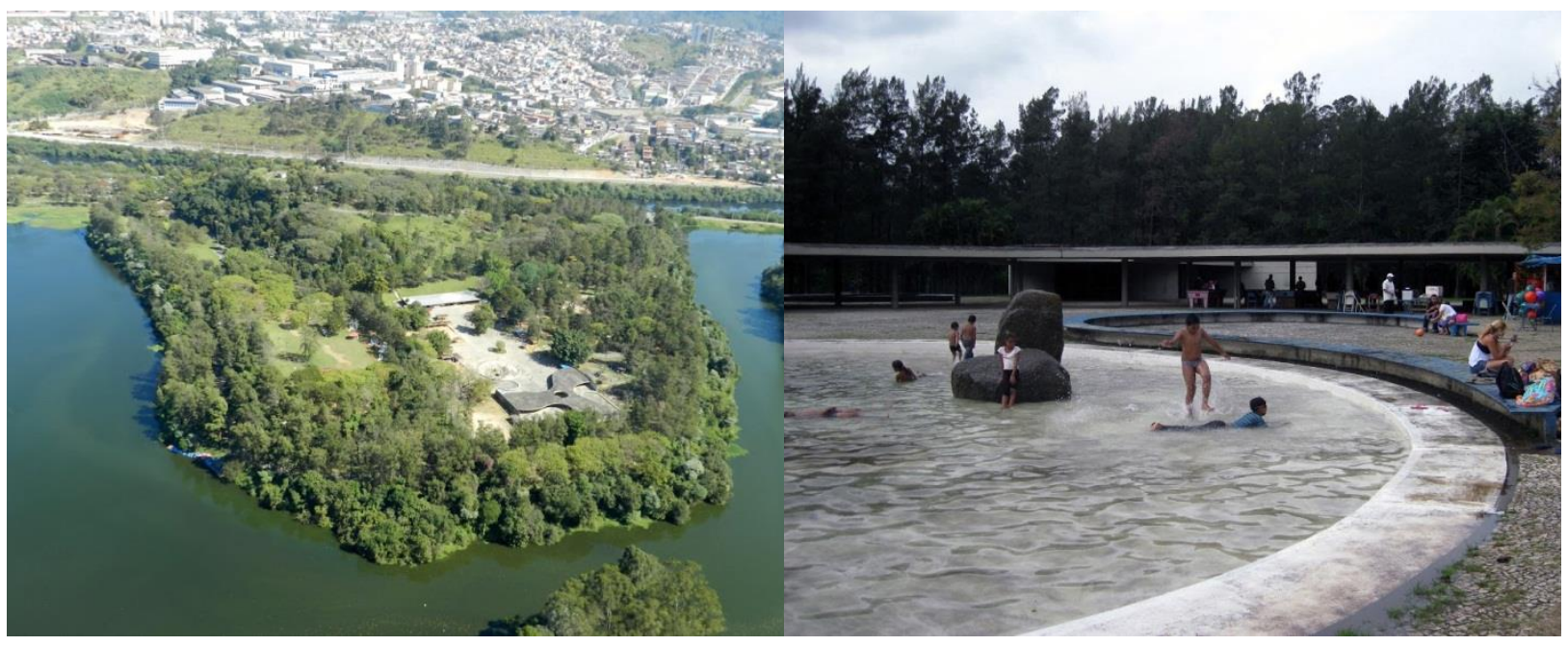

Fotos dos autores, 2013.

Outra superfície protegida sob responsabilidade do Governo do Estado é o Parque Jequitibá. Criada pelo Decreto Estadual 50.597/2006, a área encontra-se em processo de implantação em 2015, ainda sem uso como parque. As glebas da Fazenda TIZO - abreviatura para Terrenos Institucionais da Zona Oeste - foram adquiridas em 2001 pela Companhia Metropolitana de Desenvolvimento Urbano. A pressão da sociedade civil contribuiu de forma significativa para sua viabilização.

Em Jandira, município com menor quantidade de espaços livres tanto em números absolutos quanto em relação à área total de seu território, as superfícies 


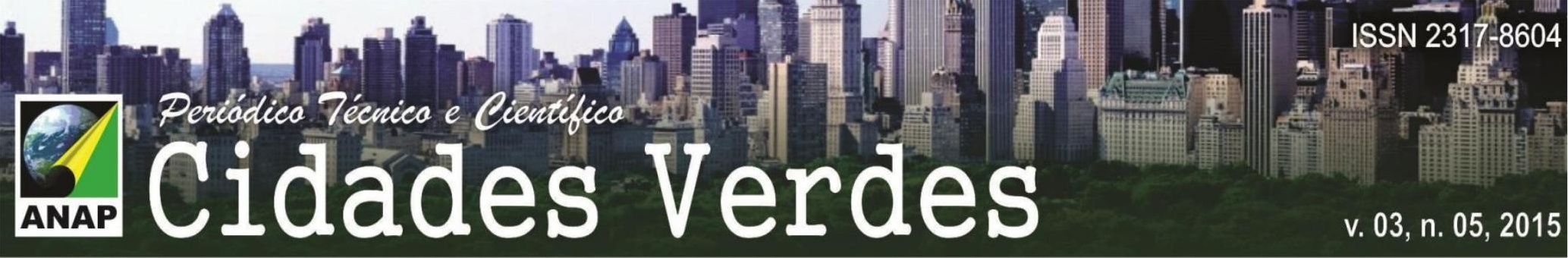

protegidas coincidem com as zonas de preservação ambiental presentes em seu Plano Diretor. Embora o município seja o mais carente e com menores recursos para implantação e manutenção de áreas ambientalmente protegidas ${ }^{6}$, duas das áreas decorrentes desse zoneamento foram efetivamente implantadas: a Área de Lazer do Trabalhador e o Portal Ecológico. Tal quantidade é significativa se for comparada a Itapevi, município vizinho que possui maior quantidade de recursos financeiros e espaços livres ambientalmente frágeis e, excluída a RPPN Sítio Ryan, não apresenta nenhuma superfície protegida efetivamente implantada ${ }^{7}$. $\bigcirc$ Portal Ecológico é um parque com cerca de $110.000 \mathrm{~m}^{2}$ inaugurado pela prefeitura de Jandira em 2009 e que preserva um dos poucos remanescentes florestais em meio à mancha urbanizada compacta e precária do município. Seu programa abrange equipamentos recreativos, um lago e trilhas de caminhada na mata.

Figura 6 (esquerda): Área de Lazer do Trabalhador, em Jandira.

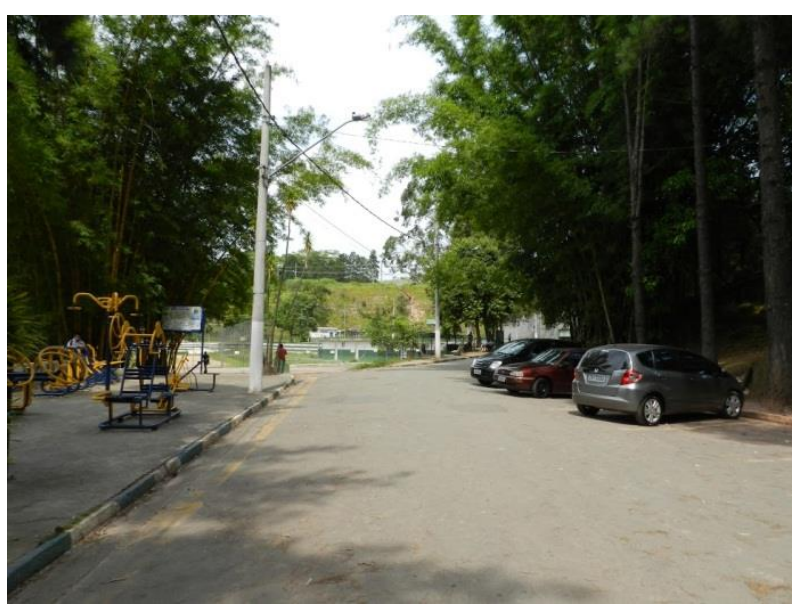

Figura 7 (direita): Portal Ecológico, em Jandira.

Fotos dos autores, 2014

Figura 8: Parque Dom José, município de Barueri.

\footnotetext{
${ }^{6}$ Cf. COELHO, Leonardo L; AMANCIO, Mayara Luísa Tebaldi. Análise comparativa das ações do Poder Público na qualificação de espaços livres nos municípios de Barueri, Itapevi e Jandira. Revista Paisagem Ambiente: ensaios. n.31, 2013.

${ }^{7}$ lbid.
} 


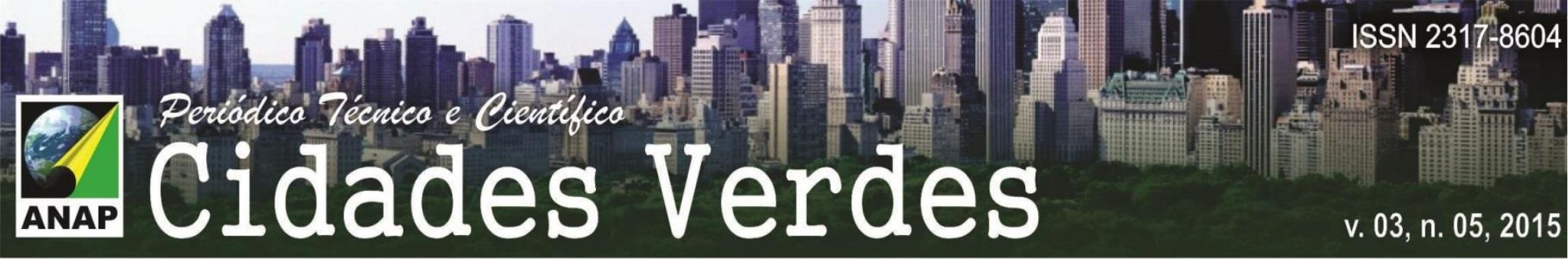

Figuras 12 e 13: Parque Linear Lagoa do Agreste.

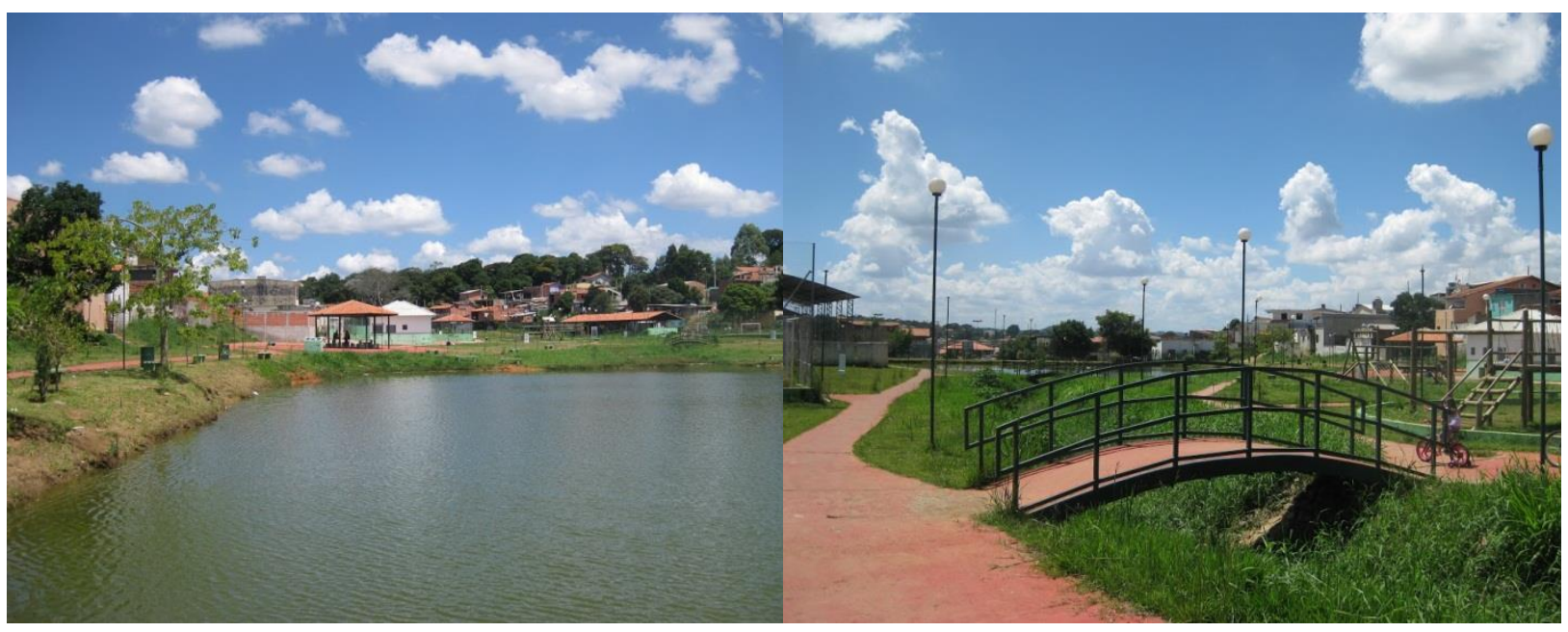

Fotos dos autores, 2014

\subsection{Superfícies protegidas não delimitadas}

As demais superfícies protegidas não definidas por perímetros específicos pelo estado ou municípios - tais como maciços de cobertura arbórea, corpos d'água e suas respectivas matas ciliares (Figura 2) - estão sujeitos ao Código Florestal $^{9}$ e à Lei da Mata Atlântica ${ }^{10}$, que estabelecem atribuições mais genéricas e não possuem delimitação espacial específica (TARDIN, 2008, p.170). Muitas dessas áreas estão inseridas em locais regidos por uma legislação que as considera como superfícies edificáveis pelas prefeituras e sua preservação fica sujeita à análise caso a caso dos órgãos de aprovação de âmbito estadual.

\footnotetext{
${ }^{9}$ Lei Federal 12.651/2012

${ }^{10}$ Lei Federal 11.428/2006
} 


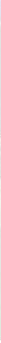

Figura 14: Superfícies protegidas (maciços de cobertura arbórea e corpos d'água) do vetor oeste da RMSP.

- Limite municipios

Vetor Oeste

- Demais municipios RMSP

- Principais corpos d'água

- Matas

- Rodovias
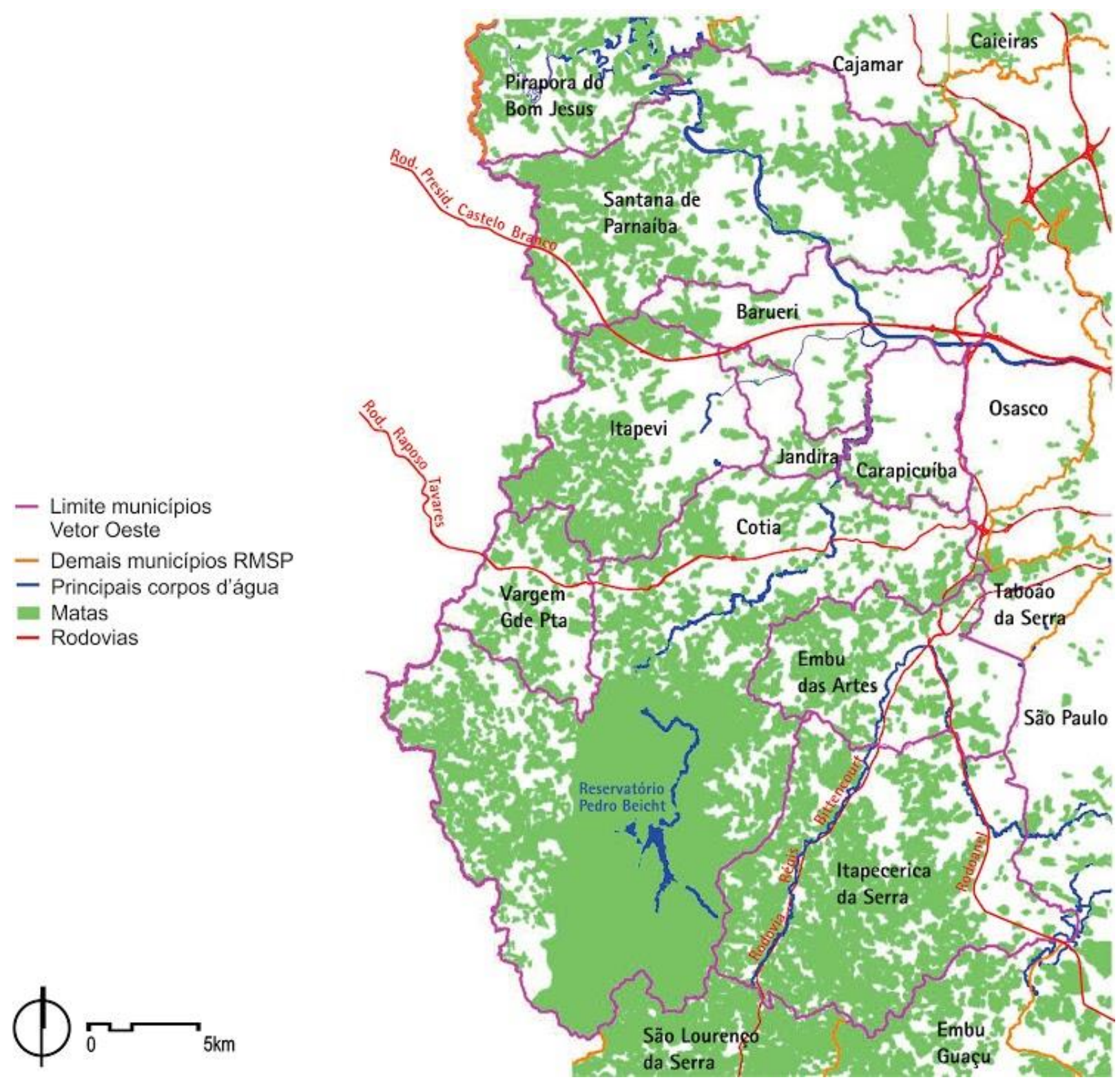

Fonte: elaborado pelos autores e por Viviane Ribeiro Viana a partir de mapeamento da EMPLASA, 2006

A falta de efetividade na aplicação desses mecanismos faz com que corpos d'água do vetor sejam objetos de ações de ocupação de suas bordas pelo próprio Poder Público. Tal situação é exemplificada pelo tamponamento de trechos 
ecológicos", pois compõem-se de bosques - alguns muito extensos - e lagos, aos quais foram acrescidas trilhas e um ou mais núcleos com equipamentos para o lazer.

Nesses parques, na maioria dos casos, a visitação é intensa e o papel destes espaços públicos é claro para a constituição da vida pública - do lazer, da convivência e da civilidade. A integridade deles está garantida pelo valor de uso.

Mas existe um estoque expressivo de áreas ambientalmente frágeis no vetor que ainda são passíveis de serem conservadas e melhor articuladas com as áreas urbanizadas existentes, algo evidenciado pela existência de mecanismos legais abrangendo aproximadamente a metade da área correspondente à soma dos municípios estudados. Entretanto, a maioria dos mecanismos legais ali incidentes não permite estabelecer conexões entre as áreas ambientalmente frágeis existentes de modo consistente. Essa falta de articulações entre as significativas áreas remanescentes, somada à falta de apropriações específicas pela população, representam a maior ameaça de degradação ambiental para o vetor, pois contribuem, por exemplo, para o processo de fragmentação e desaparecimento das manchas de cobertura arbórea existentes.

$\mathrm{Na}$ prática, com exceção dos parques urbanos, as diferentes áreas de conservação e preservação legalmente estabelecidas na região estão desprotegidas. Em que pese a falta de condições administrativas e financeiras da maioria das administrações municipais e a falta de ações de porte pelo governo do estado, a chave para este fato está no desinteresse da população.

Não se pode dizer que não haja apreciação da natureza nessas reservas que não são acessíveis, pois se assim fosse, nem sequer as leis teriam sido criadas. No entanto, elas parecem não ter um significado maior para os municípios e seus habitantes. Como se estivessem à espera de qualquer destinação. Não se observa na maior parte das áreas ambientalmente frágeis do vetor, ações de delimitação e caracterização destas terras como logradouros públicos, para reconhecimento e usufruto da sociedade. Também não há espontaneamente esta demanda, em ações de apropriação pelo público, como a visitação ou uso informal para recreação e convívio, que tornam os espaços parte do cotidiano das pessoas. É quando a 
